\title{
Monoteïsme en geweld: 'n Perspektief op die standpunt van J Assmann ${ }^{1}$
}

\author{
Prof A P B Breytenbach \\ Departement Ou-Testamentiese Wetenskap \\ Universiteit van Pretoria
}

\begin{abstract}
Monotheism and violence: A perspective on the position of $\mathbf{J}$ Assmann

The problem of monotheism and violence, as put forward by Assmann in a recent article "Monotheismus und Ikonoklasmus als politische Theologie", is addressed. Violence in a religious context more often than not emanates from a paradigm of exclusive monotheism. The origin of this kind of violence can be traced back to people in position of power who held the opinion that the truth was entrusted to them alone and that their enemies were also the enemies of their god. This also held true for interest groups in Judah. Old Testament literature promoting violence should be read critically within the broader context of books like Genesis, Ruth, Jonah and New Testament writings.
\end{abstract}

\section{INLEIDING: DIE TEORIE VAN J ASSMANN}

Jan Assmann het in 'n onlangse artikel betoog dat geweld inherent is aan monoteïstiese godsdienste. In die artikel bou hy voort op vorige navorsing wat hy gedoen het in verband met Moses as herinneringsfiguur (Assmann 1997). Assmann is nie geïnteresseerd in die historiese Moses nie, maar in Moses as 'n simboliese konstruksie wat in 'n historiese oorleweringskonteks gefigureer het. Hy stel sy vertrekpunt soos volg:

\footnotetext{
${ }^{1}$ Hierdie artikel is in verkorte vorm gelewer as voordrag by die amptelike opening van die Fakulteit Teologie, Universiteit van Pretoria op 31 Januarie 2001.
} 


\title{
Monoteisme en geweld
}

\begin{abstract}
Nun liegt die Wahrheit der Erinnerung nicht nur in dem, was ihr in der uns natürlich immer entzogenen und nur asymptotisch erreichbaren Vergangenheit de facto entsprochen haben mag.... Die Wahrheit der Erinnerung liegt auch in dem, was sie an geschichtlicher Gegenwart fundiert und beleuchtet. Wir wenden uns der Vergangenheit ja immer aus einer bestimmten Gegenwart heraus zu, unsere Fragen, unser Erkenntnisinteresse und unsere Deutungsrahmen sind von unserer Gegenwart aus bestimmt. Erinnerte Ver-gangenheit ist immer Teil einer aktuellen, gegenwartsbezogenen Semantik.
\end{abstract}

(Assmann 2000:122)

Assmann meen dat daar ' $n$ relasie aangedui kan word tussen Moses en farao Ichnaton omdat albei in die oorlewering met monoteisme in verband gebring word. Hy sien egter hierdie relasie as "eine Beziehung der Emergenz, also daß zwei kausal in keiner Weise verbundenen Erinnerungsströme im Laufe der Geschichte zusammengeflossen sind und eine Beziehung gestiftet haben..." (Assmann 2000:123). Dit is algemeen bekend dat Ichnaton na sy dood as 'n ketter beskou is, en dat daar amptelik van staatsweë pogings was om sy spore dood te vee. Assmann meen egter dat daar in wat hy noem die kollektiewe geheue die herinnering aan Ichnaton se monoteïsme wél bly voortleef het. Dít sê hy, was die voedingsbron vir tradisies wat op 'n stadium met die oorlewering oor Moses saamgegroei het en aanleiding gegee het tot legendes in die Hellenistiese tyd. Hy vind bewyse hiervoor in verskillende Egipties-Hellenistiese tekste. Flavius Josefus is seker dié belangrikste tradent van hierdie inligting. Flavius Josefus hanteer in sy Contra Apionem onder andere die vertelling van Manetho, 'n Egiptiese priester uit die tyd van Ptolemeus II. Manetho vertel die legende van die Heliopolitaanse priester Osarsip wat die leiding geneem het in 'n ikonoklastiese en teoklastiese beweging ( $\mathrm{d}$ w $\mathrm{s}$ die vernietiging van beelde en gode) en wat later die naam Moses aangeneem het. Van Osarsip sê Assmann (2000:126v): " $\mathrm{Daß}$ hinter Osarsiph eine verschobene Erinnerung an Echnaton steckt, dessen Name durch die spurlose Vernichtung der Denkmäler und die Streichung aus den Königslisten vergessen worden war, halte ich mit Eduard Meyer, Donald Redford und vielen anderen für evident."

Uit twee verskillende herinneringstrome wat saamgevloei het, het daar dus 'n Hellenistiese Moses-figuur na vore getree wat ' $n$ beeldestormer en vernietiger van 'n 
godsdienstige tradisie was. In die Egipties-Hellenistiese legendes (Assmann verwys ook na Hekataios, Strabon, Tacitus en Diodorus) verskyn Moses feitlik sonder uitsondering as politieke teoloog wat sy nuwe teologie deur wetgewing en die skepping van 'n volk in praktyk bring of wat 'n nuwe politieke orde teologies legitimeer.

Assmann (2000:135) vind in sy vergelyking van die Egipties-Hellenistiese legendes en die $\mathrm{Ou}$-Testamentiese oorlewering oor Moses punte van ooreenkoms:

Es gibt also eine Reihe gemeinsamer Punkte. Der entscheidende gemeinsame Nenner liegt in der Gestalt eines politischen Führers, der die Götter der Anderen bzw. "andere Götter" ablehnt, die Bilder verwirft und Gesetze gibt, also in einer neuartigen, ja revolutionären Verbindung von Theologie und politik bzw. politischer Theologie. Das ist mit der Formel Ikonoklasmus als politische Theologie gemeint. Es geht um die Gründung einer politischen Ordnung, in der das Göttliche auf eine nicht durch Bilder vermittelte Weise präsent ist.

Assmann dui aan dat representante van gode 'n belangrike rol gespeel het in die Egiptiese religieuse wêreld. Heilige diere en beelde is in oormaat gebruik om die goddelike magte voor te stel. Die interessante is dat representante van gode altyd die afwesigheid van gode veronderstel. Gode en goddelike magte wat deur beelde en diere gerepresenteer moet word, is ver en verborge. Daarteenoor veronderstel eksklusiewe monoteǐsme die onmiddellike teenwoordigheid van die god of goddelike mag. In die taal van die $\mathrm{Ou}$ Testament "woon JHWH in die midde van sy volk." Om dit egter moontlik te maak, moet die onreine en onvolmaakte geweer en uitgeroei word. Eksklusiewe monoteïsme gaan daarom feitlik altyd gepaard met die vernietiging van beelde en simbole van ander magte. Ikonoklasme of beeldestorming is dus in wese die vestiging van 'n politieke orde waar die goddelike op 'n wyse onmiddellik teenwoordig is. Hierdie onmiddellike teenwoordigheid van die god word juis verwerklik deur die vernietiging van die beelde. Daarmee word bevestig dat die mag, heerskappy, orde en geregtigheid deur die een en enigste god bepaal word. 
Die vernietiging van beelde en simbole beteken ook dat 'n nuwe waarheidsbegrip tot stand kom. Die nuwe waarheidsbegrip trek nuwe grense en sluit in en uit. Eksklusiewe monoteïsme hou in dat daar onderskei word tussen die ware god en die afgode, tussen waar en vals en daarom ook tussen vriend en vyand, veral op politieke terrein. Assmann (2000:137) stel dit só: "Beim Bilderverbot handelt es sich um eine Feindbestimmung im Licht der Unterscheidung von wahr und falsch." Vyande is diegene wat dwaalleer aanhang en afgode vereer. Assmann definieer dan ook die onderskeiding van vriende en vyande as die politiek van geweld. Ikonoklasme berus dus op 'n politieke teologie van geweld. Hy wys daarop dat die Ou Testament inderdaad geweldstaal gebruik as dit kom by die uitwissing van afgodediens. Voorbeelde hiervan is die Leviete wat ná die episode van die goue kalf onder die Israeliete invaar en hulle voor die voet doodmaak (Eks 32:25-35), Elia wat op Karmel die Baälprofete uitroei (1 Kon 18:40) en die kultushervorming van Josia waartydens priesterlike families om die lewe gebring word ( 2 Kon 23:4-20). Monoteïsme, sê Assmann, word in die Ou Testament deur middel van doodslag deurgevoer.

Assmann wys verder daarop dat, van die drie wêreldgodsdienste wat hulle monoteïsme tenugvoer na Abraham, slegs die Judaïsme nie fisiese geweld gepleeg het nie. Daarteenoor is die Christendom en Islam se geskiedenis vol van die geweld teen ander geloofsgroepe. Islamitiese fundamentaliste is vandag steeds vasgevang in die greep van 'n politieke teologie van geweld. Die Jode, sê Assmann, het egter die Ou-Testamentiese tekste gehumaniseer en die onderskeiding van vriend en vyand verinnerlik: Die onderskeid tussen vriend en vyand is slegs van toepassing gemaak in die eie kring in die sin dat slegs afvallige Jode teëstanders kon word. Verder is die onderskeiding van vriend en vyand van toepassing gemaak in die eie persoonlike lewe. Assmann (2000:138) stel dit soos volg: "Das Konzept des Götzendienstes, der 'Idolatrie', des Abfalls von Gott zu anderen Göttern, wurde als Inbegriff der 'Sunde' immer stärker psychologisiert und dadurch entpolitisiert." Die Jood het dus teen die heiden in die eie hart die wapens opgeneem en nie teen heidene in die politiekę wêreld nie. Daarteenoor het die Christendom en Islam deur die politieke teologie van geweld die heidene in die wêreld om hulle onderdruk. Die geweld van hulle God teenoor die ander gode het hulle die reg gegee om geweld te pleeg teenoor mense wat ander gode aanhang. Assmann (2000:139) 
sluit sy artikel af met die betekenisvolle opmerking: "Wenn man die monotheistische Idee retten will, dann muß man sie ihrer inhärenten Gewalttätigkeit entkleiden."

\section{KOMMENTAAR OP DIE STANDPUNT VAN ASSMANN}

Assmann moet in baie opsigte gelyk gegee word. Daar kan naas dié wat hy noem nog talle voorbeelde uit die $\mathrm{Ou}$ Testament aangehaal word waar ' $\mathrm{n}$ streng monoteïsme geweld teen ander legitimeer. So byvoorbeeld staan daar in Deuteronomium 13:6-16:

${ }^{6}$ Dit kan gebeur dat jou broer, jou ma se seun, of jou seun of jou dogter of jou eie vrou of jou boesemvriend jou in die geheim wil verlei en vir jou sê: "Kom ons gaan dien ander gode." ${ }^{7}$ Dit kan gode wees wat jy en jou voorvaders nie geken het nie, gode van die volke in jou omgewing, gode wat naby is of ver, gode in die een uithoek van die land of in die ander uithoek. ${ }^{8}$ Dan mag jy nie voor hom swig en na hom luister nie. Jy mag hom nie jammer kry nie. Moet hom nie verskoon en wegsteek nie. ${ }^{9} \mathrm{Jy}$ moet hom sonder meer doodmaak. Jy moet daarmee begin en dan moet die volk jou daarin bystaan. ${ }^{10} \mathrm{Jy}$ moet hom met klippe doodgooi, want hy wou jou verlei om ontrou te word aan die Here jou God wat jou uit Egipte, uit die plek van slawerny, bevry het.

"Die hele Israel moet dit hoor en bang word sodat so 'n verkeerde ding nie weer onder julle gedoen word nie.

${ }^{12-13}$ Wanneer jy hoor dat kwaadstokers gekom het in een van die stede wat die Here jou God vir jou sal gee om in te woon, en hulle sy inwoners verlei het deur hulle aan te spoor om vreemde gode te dien waarvan julle nie geweet het nie, ${ }^{14}$ moet jy die saak deeglik ondersoek en haarfyn daarna uitvra. As die gerug waar is en die afskuwelike daad wel tussen julle plaasgevind het, ${ }^{15}$ moet jy die inwoners van daardie stad sonder meer doodmaak. Die stad met alles daarin, selfs sy vee, moet as banoffer vernietig word. ${ }^{16} \mathrm{Jy}$ moet alles in die stad op die stadsplein bymekaarmaak en saam met die stad geheel en al verbrand as 'n offer aan die Here jou God. Die stad moet vir altyd 'n puinhoop bly. Dit mag nie weer herbou word nie. 
Ons lees ook in Deuteronomium 17:2-5:

\begin{abstract}
${ }^{2}$ Dit kan gebeur dat jy in een van die dorpe wat die Here jou God vir jou sal gee, 'n man of ' $n$ vrou kry wat die verbond verbreek en doen wat verkeerd is in die oë van die Here jou God ${ }^{3}$ deur ander gode te dien en te vereer: die son of die maan of enige ander hemelliggaam. Die Here het nie hierdie soort diens beveel nie. "Wanneer dit vir jou vertel word of wanneer jy dit hoor, moet jy noukeurig navraag doen daaroor en as dit waar is dat so iets afskuweliks in Israel gedoen is, ${ }^{5}$ moet jy die man of die vrou wat die verkeerde ding gedoen het, laat uitbring na die stadspoort toe en hy of sy moet daar met klippe doodgegooi word.
\end{abstract}

Dieselfde soort motivering vir geweld (naamlik monoteïsme wat hom keer teen afgodediens of die moontlikheid daarvan) vind ons in Esra 10 en Nehemia 13:23-28. Persone wat nie met suiwer Joodse vrouens getroud is nie word as vyande geïdentifiseer en uitgesluit.

Dit is wel interessant om daarop te let dat die aartsvadervertellings op enkele uitsonderings na geweldloos is. Dit hang moontlik daarmee saam dat die narratief die aartsvaders nie voorhou as eksklusiewe monoteïste nie. Hulle dien God onder verskillende name by verskillende heiligdomme. ${ }^{2}$ In die geval van Jakob sou 'n mens selfs van henoteïsme kon praat: Die ander gode word eers begrawe voordat Jakob en sy familie na Bet-El optrek (Gen 35:1-4). In Genesis 14 speel geweld egter wel 'n rol. Dit word algemeen aanvaar dat Genesis 14 ingevoeg is in die Abrahamsiklus (Van Selms 1967:199; vgl ook die afwesigheid van Gen 14 in Blum 1984) en dat die agtergrond van hierdie vertelling gesoek moet word by die Jerusalemse priesterskap (vgl Salem en Melgisedek). 'n Verdere voorbeeld van geweldadige optrede vind ons in Genesis 34 in die vertelling oor Dina en die Sigemiete. Opvallend genoeg word ook hierdie geweld verbind met die Leviete.

Ek verskil egter van Assmann as dit kom by sy standpunt oor die Judaïsme. Ek meen dat hy die saak nie genuanseerd genoeg hanteer het nie. Die Judaïsme het wel nie fisiese geweld gepleeg teen vreemdes op die skaal waarop die Christendom en Islam dit

אל שלראל אל שדי אל ביתזאל פחד יצחק אלהי השמים אל עולם 
in die eeue daarna gedoen het nie. Daar is egter talle voorbeelde van kulturele en ekonomiese geweld wat deur Jode gepleeg is. Die vroegste voorbeelde daarvan vind ons juis in Esra 10 en Nehemia 13. Verder is daar genoeg voorbeelde van "religieuse" geweld wat gepleeg is deur die ekskluwistiese tempelgemeenskap in Jerusalem. Die heel vroegste geskiedenis van die eerste Christelike gemeentes getuig ook daarvan (vgl bv Hand 5:17-41; 7:1-8:3). Die huidige konflik in Israel, sou ook as politieke geweld teenoor die Arabies-sprekende gemeenskappe beoordeel kon word.

\section{GEWELD IN DIE OU TESTAMENT}

Om terug te keer na die Ou Testament: Die eis om absolute lojaliteit wat die monoteïsme stel, kom in die Ou Testament veral tot uitdrukking in die verbond. Die klassieke verbondsdokument, die dekaloog, stel dan ook die monoteïsme en die verbod op representante as die primêre voorwaardes vir die verbondsverhouding: "Jy mag naas My geen ander gode hê nie. Jy mag nie vir jou ' $n$ beeld of enige afbeelding maak van wat in die hemel daarbo of op die aarde hieronder of in die water onder die aarde is nie" (Eks 20:34).

Eckart Otto het oortuigend aangetoon dat dele van die boek Deuterononium inhoudelik, maar selfs ook woordeliks ooreenkom met Assiriese dokumente wat die lojaliteitseed aan Asarhaddon verwoord (Otto 1999:1-90). Deuteronomium 13:2-10 asook die vervloekingspreuke in Deuteronomium 28:20-44 kom byvoorbeeld merkwaardig ooreen met die dreigemente en geweldstaal van dele van die lojaliteitseed wat afgelê moes word teenoor die Assiriese koning. Otto se teorie is dat die lojaliteitseed teenoor die Assiriese koning in die tweede helfte van die sewende eeu vC in Juda vervang is met 'n lojaliteitseed teenoor JHWH en dat dit neerslag gevind het in die boek Deuteronomium. Daaruit kan die afleiding gemaak word dat elemente van die geweldstaal in die Ou Testament hulle oorsprong buite Israel-Juda het. Belangriker is egter dat absolute lojaliteit teenoor een heerser/Heerser in die Semitiese wêreld gepaard gegaan het met dreigemente waarin geweldstaal 'n belangrike rol speel.

Die eis om lojaliteit teenoor die één God van die verbond hou dus die moontlikheid van geweld in - nie in die eerste plek teenoor vreemdes nie, maar wel teenoor die afvalliges binne die verbond. Dit word gesuggereer in die dekaloog ("Ek reken kinders 


\section{Monoteïsme en geweld}

die sondes van hulle vaders toe, selfs tot in die derde en vierde geslag wat my haat") en word volledig uitgewerk in die narratief van Eksodus, Numeri en die paranetiese gedeeltes van Levitikus en Deuteronomium (vgl bv Deut 7:1-26), veral in die sogenaamde verbondvervloekings (Lev 26; Deut 28:15-68). Hierdie "indirekte geweld" (die wraak of straf van God oor ontroues) dien natuurlik in die eerste plek as appèl tot absolute lojaliteit. In profetiese literatuur wat Israel aanspreek binne die dinkraamwerk van die verbond kom dit dikwels so voor: Die profete verwys na die geweld waaronder die hoorders in die toekoms gaan ly. Dit dien as appèl vir die keuse tot lojaliteit aan die Verbondsgod in die hede. Die probleem is egter dat mense hulle soms aanmatig om in die plek van God te tree en self die straf van God uit te voer.

In Hosea 11 vind ons ' $n$ baie besondere hantering van die eis om lojaliteit binne die verbond (Breytenbach 1979:291-313). Nadat Israel van gruwelike ontrou aangekla is (dat hulle ander gode gedien het en JHWH se toenadering afgewys het, vgl Hos 11:1-5), bly daar in terme van die verbond net een uitweg oor, naamlik die totale uitwissing van die ontroue verbondgenoot (Hos 11:6-7). Daar kom egter 'n onverwagte wending: God keer as't ware die geweld teen Homself en wend só die uitwissing van die skuldiges af (Hos 11:8-9). Hierdie dramatiese wending in die eksklusiewe monoteïsme vind op 'n besondere manier weerklank in die Nuwe-Testamentiese literatuur.

\section{DIE SIONSTEOLOGIE}

'n Voorlopige konklusie waartoe ek gekom het, is dat die eksklusiewe monoteïsme wat geweld teen buitestanders legitimeer, onder andere verbind kan word met belangegroepe in Jerusalem wat voorstanders was van die sogenaamde Sionsteologie - die oortuiging dat JHWH Hom só verbind het aan Sion dat 'n veilige toekoms vir dié plek en sy mense absoluut gewaarborg is (Van der Woude 1976:11-12, 119-121, 162-63; vgl ook Deist 1995:72-73). Daar is talle voorbeelde uit voor-eksiliese en na-eksiliese literatuur waar 'n duidelike verband aangedui kan word tussen die eksklusiewe monoteïsme van Jerusalem en geweld teen buitestanders. Psalm 110 is hiervan 'n goeie voorbeeld: Die koning wat die beskermheer is van die kultus op Sion (vgl "die priesterorde van Melgisedek") sal konings verdelg en die wêreld vol lyke laat lê. Gedeeltes soos Miga 4:11-13; 5:4-5 en 
5:7-8 bied ook goeie voorbeelde van geweld wat bedink of beplan word vanuit die paradigma van die Sionsteologie (Van der Woude 1976:172-183).

'n Wesenlike element van die Sionsteologie was die oortuiging dat die kultuspersoneel van die tempel in Jerusalem oor die waarheid beskik en dit beheer. Hierdie waarheidsbeskouing het, soos reeds aangedui, selfs JHWH gebind. Vanuit hierdie waarheidsbeskouing is 'n bepaalde orde gevestig, anders gesê, is vriende en vyande onderskei. Hierdie politieke teologie van geweld was die agtergrond van die etniese en religieuse suiweringsveldtogte in die tyd van Josia, Esra en Nehemia en dit was waarskynlik ook die rede vir die ontstaan van die Samaritaanse en Qumraanse religieuse gemeenskappe (Kippenberg 1971:57-59; Van der Woude 1957:46). Die effek van hierdie "beheer oor die waarheid" kan ook in die Nuwe Testament duidelik gesien word.

\section{DIE NUWE-TESTAMENTIESE KERUGMA}

Die wese van die Nuwe-Testamentiese kerugma staan plankdwars op die grein van die eksklusiewe monoteïsme. Die uitreik na veronregtes (vgl Bultmann [1960] 1965:11), die opdrag dat 'n mens jou vyand moet liefhê, die openheid teenoor vreemdes (vgl Theissen 1999:66-68) en die oortuiging dat die waarheid 'n persoon, Jesus van Nasaret is (kyk o a 2 Kor 11:10; vgl Van Aarde 2000:918-921), gaan direk in teen die eksklusiewe monoteïsme met sy waarheidsbeskouing, sy direkte toegang tot God (vgl Crossan 1991:423), sy identifisering van vriend en vyand en sy politieke teologie van geweld.

Volgens die evangelies het Jesus Homself aangebied as representant van God. In terme van die eksklusiewe monoteïsme moet enige representant vernietig word. Gesien vanuit 'n godsdiens-fenomenologiese hoek, was die kruisiging van Jesus van Nasaret 'n vorm van ikonoklasme (vgl Funk 1996:44): Alle representante van God moet naamlik vernietig word omdat die bestaan daarvan die onmiddellike teenwoordigheid van God en daarmee ook die direkte toegang tot Hom deur die eksklusiewe groep, loën. Die bestaan van 'n representant neem die grond vir die beheer oor die waarheid onder die eksklusiewe groep uit. 


\section{DIE BELANG VAN ASSMANN SE STANDPUNT IN DIE HEDE}

Die onlogiese in die geskiedenis van die kerk en die Christendom is dat, met die Nuwe Testament as deel van die kanon, geweld in die geskiedenis dikwels teologies gelegitimeer is, en dat ' $n$ politieke teologie die bepalende paradigma geword het. Die gevare wat 'n eksklusiewe monoteïsme inhou is wesenlik tot op die huidige dag. Hiervan is, soos reeds aangedui, die Islamitiese fundamentalisme met sy politieke teologie van geweld 'n sprekende voorbeeld. Die belydenis "Daar is geen God behalwe Allah nie, en Mohammed is sy profeet," bied die grond daarvoor.

Die standpunt van Assmann oor monoteïsme en geweld is uiters aktueel. Dit kan by geloofsgroepe wat geweld godsdienstig legitimeer die insig bring dat dit in hulle optrede nie gaan oor die suiwerheid van die bepaalde godsdiens of geloof nie, maar oor die verskansing van eie magsposisies. Verder kan Assmann se standpunt ' $n$ kritiese lees van die Ou Testament bevorder.

In die kerklike milieu waarin ons onsself bevind kom die gevare van eksklusiewe monoteïsme tot uitdrukking in wat genoem word burgerlike godsdiens. Daaronder verstaan ek die geloof dat God Hom skaar aan die kant van die bepaalde eie groep. Op só 'n basis gedy die oortuiging dat die band met en die onmiddellike toegang tot God beheer oor die waarheid verskaf sowel as die oortuiging dat die eie vyande ook God se vyande is en dat geweld teenoor hulle daarom geregverdig is.

Teenoor 'n burgerlike godsdiens staan Ou-Testamentiese geskrifte soos Genesis, Hosea, Jona, Rut en talle ander waarin die soewereiniteit van God téénoor menslike belange en sy onverklaarbare liefde vir mense ongeag hulle posisie, gehandhaaf word. Teenoor ' $n$ burgerlike godsdiens staan veral die Nuwe Testament waarin, binne die raamwerk van die monoteïsme, geweld teen vyande en indirekte geweld van God teenoor die ontroues, oorwin word in die persoon, lewe, dood en opstanding van Jesus van Nasaret. Hierdie soort monoteïsme, waarin die een God self die geweld van die wêreld dra, bied hoop aan 'n wêreld waarin geweld aan die orde van die dag is.

\section{TEN SLOTTE}

Ek dra graag hierdie artikel op aan professor Gert Pelser, ' $n$ man wat in die beoefening van sy teologie nooit bang was om die konsekwensies van akademiese navorsing vir die geloof te trek nie. 


\section{Literatuurverwysings}

Assmann, J 1997. Moses the Egyptian: The memory of Egypt in Western monotheism. Cambridge: Harvard University Press.

- 2000. Monotheismus und Ikonoklasmus als politische Theologie, in Otto, E (Hrsg), Ägypten und das Alte Testament. Stuttgart: Bibelwerk.

Blum, E 1984. Die Komposition der Vätergeschichte. Neukirchen-Vluyn: Neukirchener Verlag.

Breytenbach, A P B 1979. Die verband tussen en die ontwikkeling in die profetiese uitsprake in die boek Hosea. Ongepubliseerde DD-proefskrif, Universiteit van Pretoria.

Bultmann,.R [1960] 1965. Das Verhältnis der urchristlichen Christusbotschaft zum historischen Jesus. 4.Auflage. Heidelberg: Carl Winter Universitätsverlag.

Crossan, J D 1991. The historical Jesus: The life of a Mediterranean Jewish peasant. San Francisco: Harper Collins.

Deist, F E 1995. Canonical literature: Some ideology-critical observations, in Nel, P J en Van den Berg, D J, Concepts of textuality and religious texts. Bloemfontein: UOVS. (Acta Academica, Supplement I.)

Funk, R W 1996. Honest to Jesus: Jesus for a new millennium. San Francisco: Harper Collins. (A Polebridge Press Book.)

Kippenberg, H G 1971. Garizim und Synagage. Berlyn: Walter de Gruyter.

Otto, E 1999. Das Deuteronomium. Berlyn: Walter de Gruyter.

Theissen, G 1999. A theory of primitive Christian religion, tr by J Bowden.

London: SCM.

Van Aarde, A G 2000. Besinning oor die interpretasie van die geloof wat in die belydenis van die maagdelike verwekking van Jesus geleer word. HTS 56(4), 905-934.

Van der Woude, A S 1957. Die messianische Vorstellungen der Gemeinde von Qumran. Assen: Van Gorcum. (Studia semitica Neerlandica.)

- 1976. Micha. Nijkerk: G F Callenbach.

Van Selms, A 1967. Genesis, deel I. Nijkerk: G F Callenbach. 